\title{
A CONCEPTUAL FRAMEWORK FOR THE CERTIFICATION OF LASER POWDER BED FUSION PROCESS QUALITY MANAGEMENT SYSTEMS FOR AEROSPACE APPLICATIONS
}

\author{
D.W. Gibbons ${ }^{1 \# *} \&$ A.F. van der Merwe ${ }^{1}$
}

\section{ARTICLE INFO}

$\begin{array}{lr}\text { Article details } & \\ \text { Submitted by authors } & 17 \text { Mar } 2020 \\ \text { Accepted for publication } & 5 \text { Jan } 2021 \\ \text { Available online } & 28 \text { May } 2021 \\ \end{array}$

\section{Contact details}

* Corresponding author 18276342@sun.ac.za

Author affiliations

1 Department of Industrial Engineering, Stellenbosch University, South Africa

\# $\quad$ Author was enrolled for an MEng (Industrial) in the Department of Industrial Engineering at Stellenbosch University, South Africa

\section{ORCID® identifiers}

D.W. Gibbons

https://orcid.org/0000-0002-7641-4221

A.F. van der Merwe

https://orcid.org/0000-0002-0688-1254

DOI

http://dx.doi.org/10.7166/32-1-2342

\section{ABSTRACT}

This study aims to develop a conceptual framework for the certification of laser powder bed fusion quality management systems for aerospace applications. This research is structured around industry standards and best practices. The developed framework consists of a process map that identifies the required processes and activities for the realisation of parts. Industry standards and best practices are referenced to form standard operating procedures. The framework was presented to subject matter experts within the industry and academia, whose feedback was positive.

\section{OPSOMMING}

Hierdie studie stel 'n konseptuele raamwerk voor vir die sertifisering van laserpoeierbed laagvervaardigingsproses kwaliteitsbestuurstelsels vir lugen ruimtevaart toepassings. Hierdie navorsing is gestruktureer rondom bedryfstandaarde en beste praktyke. Die ontwikkelde raamwerk bestaan uit 'n proseskaart wat die vereiste prosesse en aktiwiteite vir die realisering van onderdele identifiseer. Daar word verwys na bedryfstandaarde en beste praktyke in die vorm van standaardprosedures. Die raamwerk was aangebied aan industrie- en akademie vakkundiges, en die terugvoer was positief.

\section{INTRODUCTION}

The qualification and certification of additively manufactured (AM) parts is currently a barrier to entry for such parts in the aerospace field. According to the Wohlers Report 2019, the aerospace industry is one of the main adopters of $A M$, and currently accounts for 17.7 per cent of the $A M$ industry [1]. In a survey commissioned by Defence IQ in 2016 involving $126 \mathrm{AM}$ and aerospace industry experts, 76 per cent identified the certification of parts as one of the key challenges to the full adoption of $A M$ in the aerospace field over the next decade [2]. Additional challenges highlighted in this study were material quality and the standardisation of both material and AM processes [2]. These challenges are reiterated in the Standardization Roadmap for Additive Manufacturing by the America Makes \& ANSI Additive Manufacturing Standardization Collaborative (AMSC) [3].

This study aims to develop a conceptual framework for the certification of parts manufactured via the laser powder bed fusion (LPBF) AM process for aerospace applications. Three research objectives are considered:

1. To identify the certification requirements for an $A M$ company expanding its quality management system (QMS) from ISO 13485 to include AS 9100D requirements [4][5].

2. To develop a value chain for the realisation of aerospace parts manufactured via LPBF.

3. To modularise the value chain into processes and activities and standardisation in the form of standard operating procedures (SOP). 
'Qualification' and 'certification' are terms that are often mistakenly used interchangeably when referring to aerospace parts and production, and definitions of such terms tend to differ depending on the industry and organisation involved. This ambiguity is highlighted as a gap in the Standardization roadmap for additive manufacturing by AMSC [3]. In this roadmap, 'qualification' is defined as "ensuring stability to meet functional requirements in a repeatable manner, or assuring the desired outcome of a defined process", and 'certification' is defined as "third-party evidence related to products, processes, or persons that conveys the assurance that specified requirements have been demonstrated". Det Norske Veritas (DNV) defines 'qualification' as ensuring that the design, material, or product meets specified requirements during the development and testing phase, and 'certification' as ensuring that the material, product, or component fulfils the specified technical requirements at the end of the development phase or during production [6]. A component differs from a part, as a component requires operational and airworthiness certification, and typically consists of certified parts. This certification is performed by aerospace regulatory authorities such as the Federal Aviation Administration (FAA) and the European Union Aviation Safety Agency (EASA) on the original equipment manufacturer (OEM).

Because of this confusion over terminology, this study provides its own definition of qualification and certification. 'Qualification' is defined in the context of this study as the internal process of proving that material, part, operator, process, equipment, or the operating environment can fulfil requirements prior to regular production while 'certification' is defined in the context of this study as the process of providing documented evidence that the material, part, or facility meets the technical requirements for the applicable industry, and requires that all qualification processes be performed as a prerequisite. The certification of material and parts can be performed internally by issuing a certificate of conformance $(\mathrm{CoC})$ if the test facility equipment is calibrated by an organisation with certification in accordance with ISO 17025 , whereas facility certification is performed by a third-party accredited registrar in accordance with AS 9100D for aerospace.

\subsection{Review of the related literature}

The development of standards for $A M$ is important for the full adoption of $A M$ in industry. Monzón, Ortega, Martínez and Ortega [7] presented the state of standardisation in the AM industry, focusing on ISO and ASTM standards and publicly available standardisation roadmaps. They highlighted that there is a need for industry-specific standards to facilitate the growth of $A M$ in industries such as aerospace, medical, and automotive [7]. Krueger [8] reviewed the state of AM standardisation in the aerospace industry, noting the progress made by the German Institute for Standardization (DIN). Krueger noted that standardisation of AM for aerospace is being undertaken by both national and international standards development organisations [8]. The Standardization roadmap for additive manufacturing presents the gaps in the AM standardisation landscape, and identifies the importance of industry-specific standards and conformance procedures [3].

Taylor, Manzo, and Flansburg [9] proposed a certification strategy for structural AM parts based on the building block approach that is used by the FAA for certification testing of aircraft and subassemblies, and that is aimed at type certificate holders. This study focuses on certification during the design process, and is developed by using lessons learnt from the certification of aircraft components manufactured via traditional means [9]. Portolés et al. [10] presented a qualification procedure for aerospace parts manufactured via electron-beam melting (EBM). In their paper, nine individual studies are performed, each to address a certain focus area of the qualification procedure. An aerospace bracket is manufactured and tested to be in accordance with industry standards following the procedure presented [10]. More recently, O'Brien [11] proposed a qualification strategy for AM space parts based on a risk management approach and determining manufacturing readiness levels. O'Brien [11] referenced the National Aeronautics and Space Administration (NASA) and the United States Air Force and Defense Production Act case studies, all of which focus on reducing variability in the AM process. Design of experiments (DOE) and statistical process control (SPC) are proposed as methods to reduce variability in the AM process and to qualify parts for space applications [11].

\subsection{Aerospace applications of $A M$}

Of the companies implementing AM in their manufacturing facilities, General Electric (GE) aviation is touted as one of the industry leaders. A well-known case study is the production of the fuel nozzle for the leading edge aviation propulsion (LEAP) engine. Currently, GE has manufactured over 30000 of these fuel nozzles via AM [1]. Premium AEROTEC manufactured titanium pipe elbows for the Airbus A400M. Production of this part began in late 2016, and was the first serial part to obtain airworthiness certification. Premium AEROTEC also manufactured the first topology-optimised Airbus A320 part in 2018; this was also 
manufactured in titanium [1]. Meneghin et al. [12] provided proof that, with adequate post-processing, such Premium AEROTEC parts exhibited improved fatigue behaviour and similar crack propagation rates as the specification for forged titanium for aerospace applications.

\section{METHODOLOGY}

The methodology presented in this study is based on the 'three levels of performance approach' presented in the book Improving performance: How to manage the white space on the organizational chart [13]. This approach views the organisation as a system with three levels; organisational, process, and activity. On each of these levels, goals need to be set, procedures and components need to be designed, and effective management practices need to be implemented to ensure that the goals are achieved [13]. These organisational levels correlate directly with the hierarchical structure of the organisation's QMS (Figure 1). Each objective is intended to fulfil each of the organisational levels in a top-down approach.

As certification in accordance with AS 9100D is a requirement when manufacturing parts for aerospace applications, the framework developed in this study aims to meet the critical requirements of this standard. This study has aligned itself with the current aims of the AM industry in South Africa, and specifically to develop an understanding of metal $A M$ for medical and aerospace applications [14]. As the medical AM industry is well-established in South Africa, this industry is benchmarked as the 'as-is' state for this study, and the certification of metal AM for aerospace is the 'to-be' state.

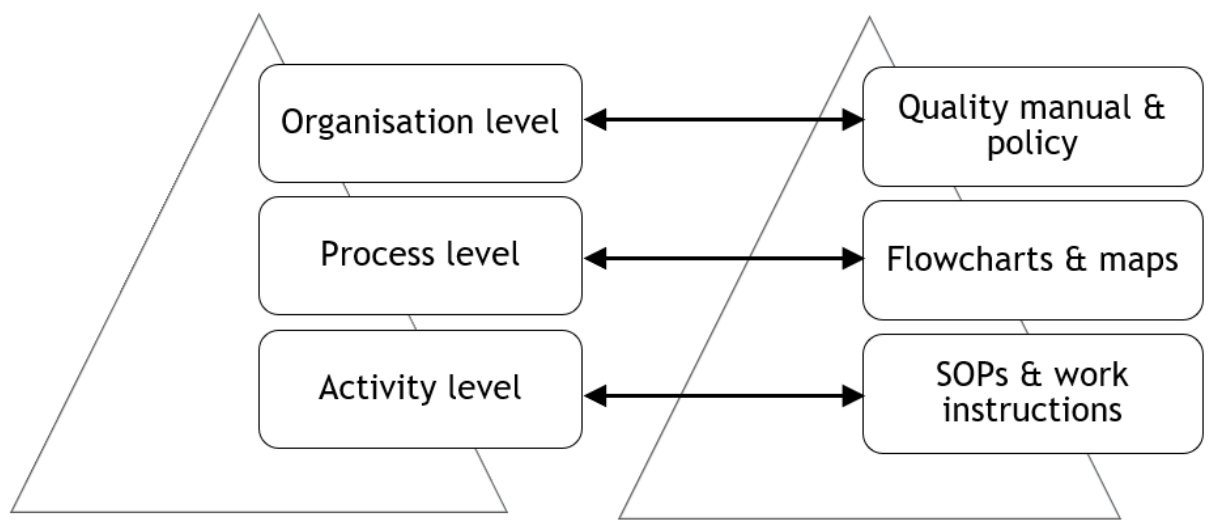

Figure 1: Organisational levels and corresponding QMS documentation

\subsection{Organisational level}

The risk management technique presented in the ISO 31000 standard is applied to identify high risks when expanding an organisation's QMS from ISO 13485 to include the requirements of AS 9100D [15]. This technique has four aspects; identification, analysis, evaluation, and treatment.

\subsubsection{Risk identification}

Risk identification is performed using a gap analysis between ISO 13485 and AS 9100D. The gap analysis defined by The Open Group Architecture Framework (TOGAF) is applied in the form of a comparison matrix [16]. ISO 13485 is the as-is state, and AS $9100 \mathrm{D}$ is the to-be state.

\subsubsection{Risk analysis}

Once the risks have been identified, they are analysed by calculating a conformance score. As ISO 13485 and AS 9100D are based on the ISO 9001 QMS standard, both standards have a set of similar requirements and are structured similarly. This structure consists of main clauses, which are divided into sub-clauses and then requirements. The conformance score is calculated for each sub-clause as a percentage of the ISO 13485 requirements that correlate with the total requirements of AS $9100 \mathrm{D}$ for the sub-clause in question. A nonconformance score is then calculated by subtracting the conformance score from 100 .

\subsubsection{Risk evaluation}

Risk evaluation aims to assist with decision-making by evaluating the outcomes of the risk analysis. The nonconformance scores are ranked according to their severity, as indicated in Table 1. 
Table 1: Nonconformance score evaluation

\begin{tabular}{|l|l|l|l|}
\hline Symbol & Indicator & Description & Range \\
\hline F & & $\mathrm{F}-$ Fulfilled & $\mathrm{x}=0$ \\
\hline VL & & $\mathrm{VL}-$ Very low & $0<\mathrm{x}<=20$ \\
\hline L & & $\mathrm{L}-$ Low & $20<\mathrm{x}<=40$ \\
\hline M & & $\mathrm{M}-$ Medium & $40<\mathrm{x}<=60$ \\
\hline H & & $\mathrm{H}-$ High & $60<\mathrm{x}<=80$ \\
\hline VH & & VH - Very high & $80<\mathrm{x}<100$ \\
\hline G & & G - Gap & $\mathrm{X}=100$ \\
\hline
\end{tabular}

\subsubsection{Risk treatment}

The identified high risks are to be addressed first, as these form the organisational goals that need to be met. Treatments are provided for these high risks based on industry standards and best practices. A risk treatment strategy is designed, and considerations are provided on how this strategy needs to be managed to meet the set goals.

\subsection{Process level}

To address the process level of the organisation, industry leaders in the $A M$ and aerospace fields in South Africa are benchmarked. Figure 2 presents the benchmarking approach that is applied.

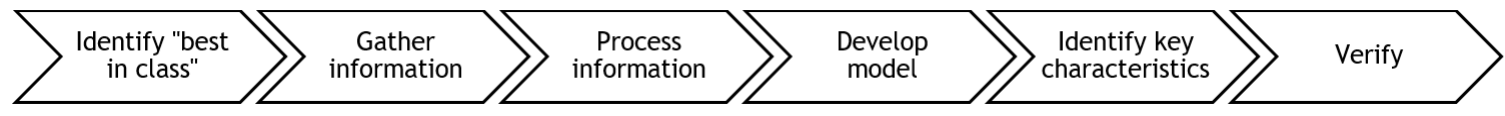

Figure 2: Benchmarking approach

Two industry partners were identified as 'best in class'. The first is a company with ISO 13485 certification to manufacture medical devices via LPBF, and the second is a company with AS 9100D certification to manufacture parts via CNC milling. Information was gathered by performing site visits and meeting with management from the respective companies. The information was then processed to identify information that is critical to the $A M$ and milling processes; from this information process maps were developed using Microsoft Visio, and in accordance with ISO 5807 for process notation [17]. From these process maps, key characteristics (KCs) of both the LPBF and the aerospace part realisation process were identified. For verification, the process map was sent to a member of the management from both companies for their review. Any suggested changes were made and verified. After the verification phase, the KCs were synthesised to develop a process map to represent the high-level aerospace LPBF value chain (VC). Figure 3 presents this synthesis process. The goal for the process level of the organisation was to provide a systematic and standardised approach to the realisation of organisational objectives. The benchmarking and synthesis approach presented in this section was used to design a process to realise these goals.

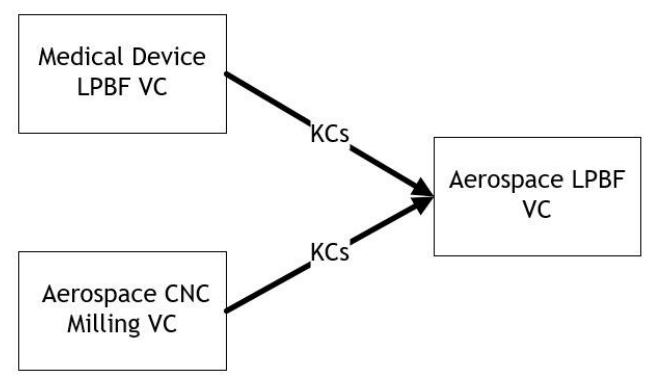

Figure 3: Aerospace VC synthesis

\subsection{Activity level}

To address the activity level of the organisation, the high-level aerospace LPBF VC was modularised into sub-processes and activities to depict a step-by-step approach to realising aerospace parts manufactured via LPBF. This was performed by process standardisation. De Vries [18] defines such standardisation processes as the process of standardising a product, process, or service, and ensuring that these can be reproduced with repeated quality and stability, often through the application of industry standards and best practices [17]. The standardisation of new processes, such as AM, helps to identify the root causes of problems, as these causes are easily identified when the standardised process is repeated. The process 
standardisation approach followed in this study is based on the approach presented by Münstermann and Weitzel [19] in which a four-step approach is presented:

- $\quad$ Document the high-level process.

- Modularise the process into sub-processes and activities.

- Isolate the process specifics.

- $\quad$ Ensure process excellence by homogenising against 'best in class'.

The approach used to standardise the high-level aerospace LPBF process in this study is presented in Figure 4. The goal of this approach is to support the process level of the organisation and to design a process depicting the activities needed to meet such goals.

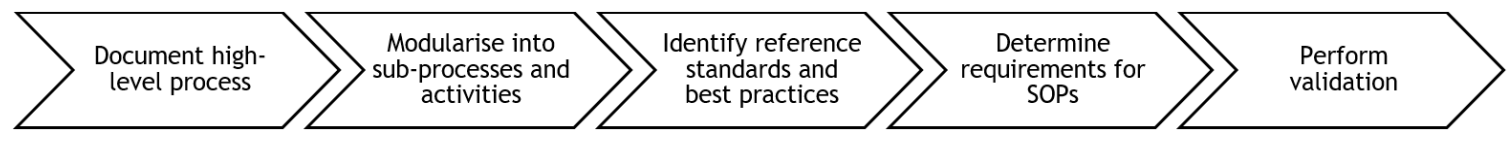

Figure 4: Process standardisation approach

\subsubsection{Document the high-level process}

The high-level process is mapped when addressing the process level of the organisation. Through synthesising the KCs determined from the benchmarking process, the high-level aerospace LPBF VC is mapped.

\subsubsection{Modularise into sub-processes and activities}

The high-level process is modularised into sub-processes and activities to present a step-by-step approach to the realisation of aerospace parts via the LPBF process. The sub-processes and activities are categorised into swim lanes, and fulfil all the KCs identified in the benchmarking process presented in Figure 2 . The output of this process is the aerospace LPBF process map.

\subsubsection{Identify reference standards and best practices}

The identification of industry standards and best practices is performed in each section of the aerospace LPBF process map. The standards and best practice literature were identified by performing a review of industry standardisation roadmaps, interviewing subject matter experts (referred to as 'experts' in this study), and searching standard-developing organisations' (SDO) websites. The identified standards and best practices were then assessed and allocated to the relevant sections of the aerospace LPBF process map.

\subsubsection{Determine requirements for SOPs}

The requirements for SOPs are determined by assessing the identified industry standards and best practices. These requirements are determined for each sub-process or activity in the aerospace LPBF process map, and assigned a unique identifier to structure the SOP documentation systematically in the organisation's QMS. Figure 5 presents the coding structure for the SOPs, and Table 2 describes the SOP codes, categorised into the respective phases of the aerospace LPBF part realisation process.

Table 2: SOP code descriptions

\begin{tabular}{|l|l|l|}
\hline QMS & SOP & $X X X$ \\
\hline
\end{tabular}

Figure 5: SOP coding structure

\begin{tabular}{|l|l|}
\hline Code & Category \\
\hline $1 \mathrm{xx}$ & Planning and risk management \\
\hline $2 \mathrm{xx}$ & Powder management and procurement \\
\hline $3 \mathrm{xx}$ & System setup \\
\hline $4 \mathrm{xx}$ & Additive manufacturing process \\
\hline $5 \mathrm{xx}$ & Post-processing \\
\hline $6 \mathrm{xx}$ & Testing and inspection \\
\hline $7 \mathrm{xx}$ & Packaging and delivery \\
\hline $0 \mathrm{xx}$ & Overall procedures \\
\hline
\end{tabular}

\subsubsection{Perform validation}

The output of the process standardisation approach presented in this section is a process map depicting the aerospace LPBF part realisation process, and the documented requirements for SOPs included industry 
standards and best practices. These outputs form the certification framework, and need to be validated to ensure that the research that has been conducted is methodologically sound and appropriate [20]. Validation was performed by interviewing experts to ascertain whether the framework presented in this study could meet the requirements for certification in the industry. The experts were selected for their expertise in either the aerospace or the AM industry, and they were interviewed in a semi-structured way. All the experts who took part in the validation process form part of the wider research group. Table 3 presents the scoring system that the experts used to validate the proposed framework.

Table 3: Validation scoring system

\begin{tabular}{|c|c|c|c|c|}
\hline 1 & 2 & 3 & 4 & 5 \\
\hline Very poor & Not good & Moderate & Good & High \\
\hline
\end{tabular}

\section{RESULTS \& FINDINGS}

The results and findings of this study are presented in the order in which they were obtained, as presented in the methodology in section 3.

\subsection{Organisational level}

The output of the gap analysis comparing ISO 13485 and AS 9100D is presented in Figure 6. The comparison matrix in this figure is summarised to the first sub-clauses. Four sub-clauses are classified as high-risk, and one is classified as very high risk. The requirements of these clauses must be fulfilled first when organisations aim to expand their ISO 13485 QMS to include the AS 9100D requirements. The QMS documentation must be developed to improve and standardise the organisation's processes and activities, and not just to obtain certification. Therefore, the QMS documentation must be 'living documentation', and must be reviewed periodically by the organisation.

A thorough assessment of the organisation's records is needed to prove to certification authorities that its practices are compliant with the QMS requirements. The organisation will need either to include the additional requirements of $A S 9100 D$ in their existing quality manual or to develop a separate quality manual specifically to fulfil the requirements of AS $9100 \mathrm{D}$. The context of the organisation needs to be redefined in an aerospace context, including the organisational policy and objectives.

The findings of the organisational level were published as part of a conference paper and presented at an international AM conference. This paper was subject to a double blind peer-review process [21].

\subsection{Process level}

By performing a benchmarking process on the AM medical device and CNC milling aerospace companies, a clear difference between the two-part realisation processes was identified. The AM medical device company was involved at more stages of the supply chain than the CNC milling aerospace company was, owing to the complex, multi-tiered supply chains involved in the realisation of aerospace parts and products. By combining the KCs identified in the benchmarking process, the aerospace LPBF VC was developed, as presented in Figure 7. This process map presents the high-level processes involved in producing aerospace parts via the LPBF process.

The primary processes form the centre of the VC start with planning and risk management, and end after packaging and delivery has been completed. Secondary processes run parallel to the primary processes, and include supplier management and procurement, storage and handling management, machine installation and qualification, in-process monitoring, and retention of production documentation and reference parts. Two feedback loops have been implemented: the first is the feedback of unused powder feedstock to be recycled and reused by the powder management process, and the second is the feedback of information about the lessons learnt from each production run into the planning and risk management process to ensure that the system is continuously improving. Operating environment management, operator training, and maintenance and calibration were identified as additional secondary processes, as these influence either the VC as a whole or many of the processes in the VC. 


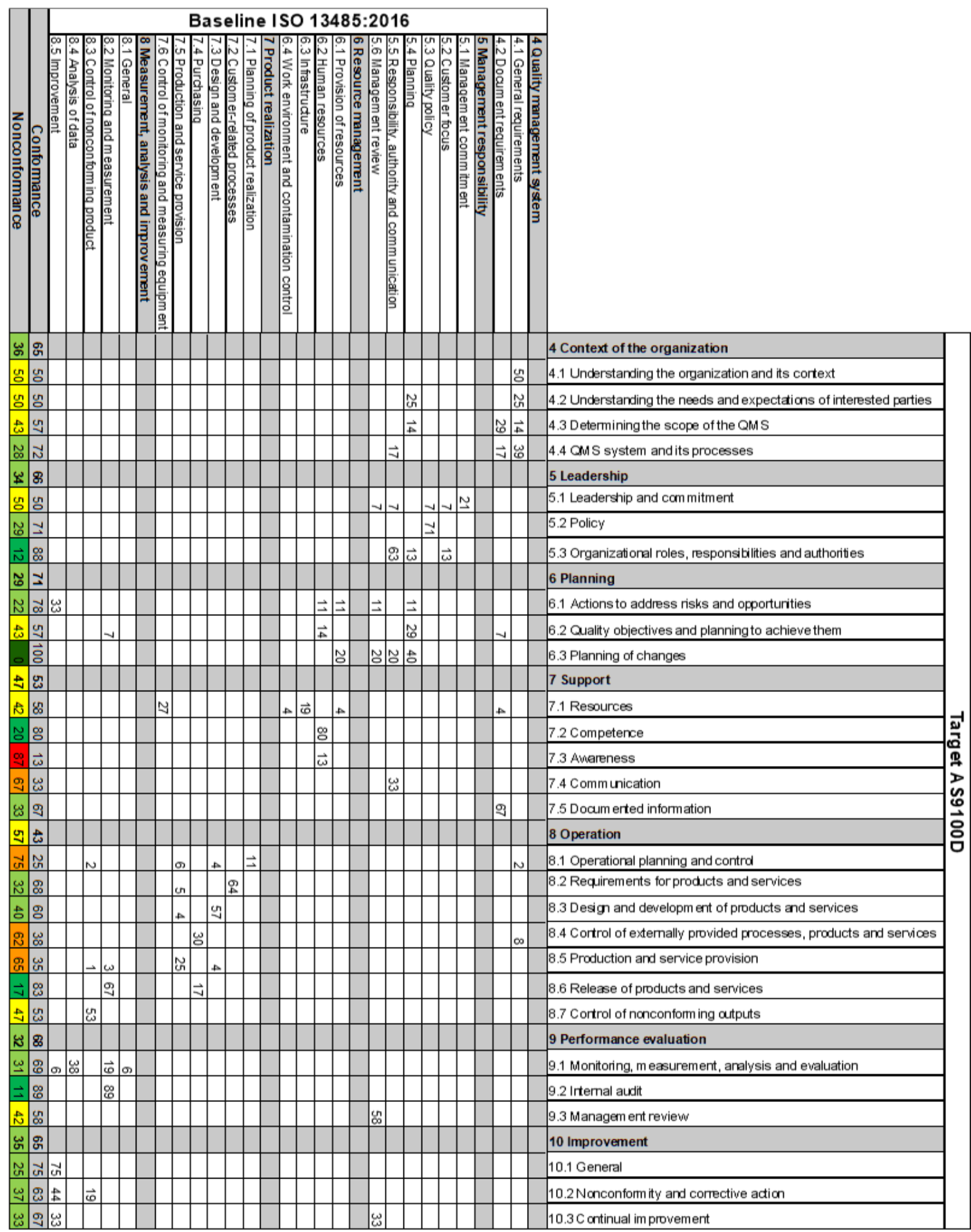

Figure 6: Gap analysis comparing ISO 13485 and AS 9100D [21] 


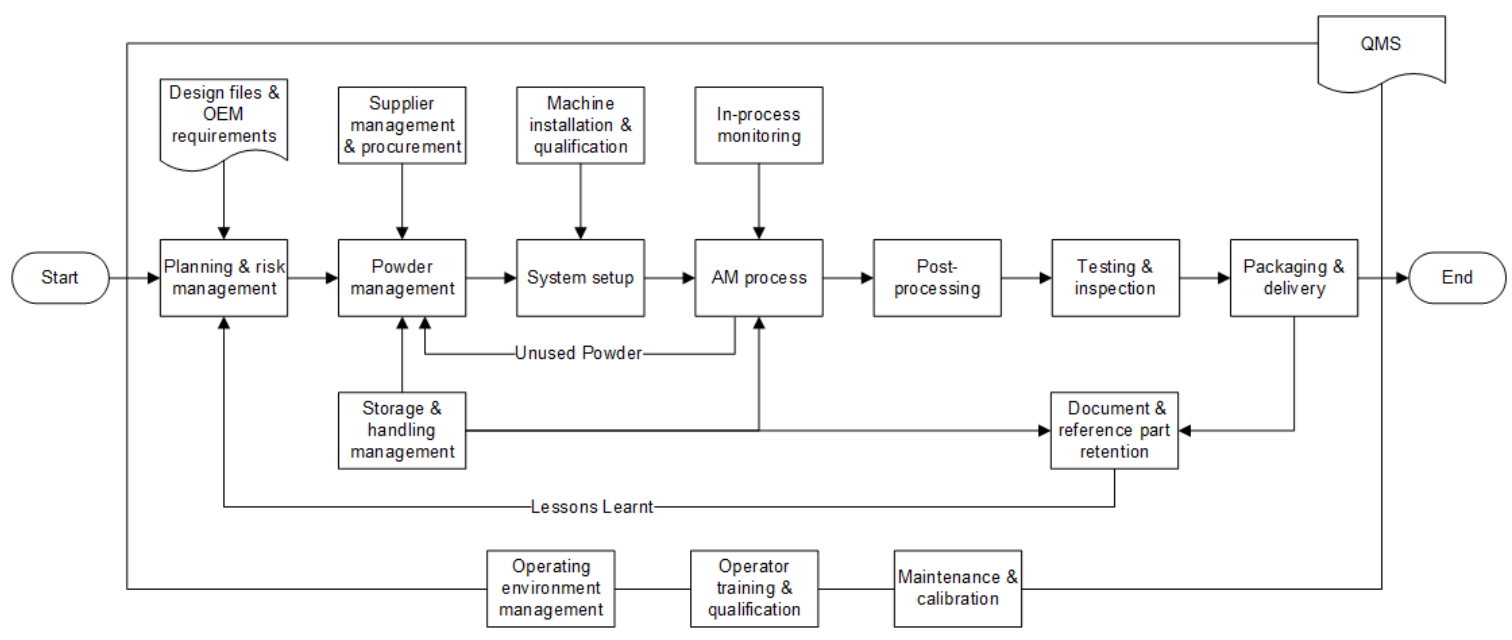

Figure 7: Aerospace LPBF VC

\subsection{Activity level}

Following the process standardisation approach, the high-level aerospace LPBF process is mapped in Figure 7. This process was modularised into sub-processes and activities as presented in Figure 8. These subprocesses and activities were categorised into the seven phases that each part manufactured passed through. Documenting the activity level helps to meet the operational requirements of AS 9100D. Table 3 presents an example of an SOP. Presentation of all developed and reviewed SOPs is not feasible due to space constraints.

\subsubsection{Planning and risk management}

The planning and risk management phase is performed when an OEM places an order for a part to be manufactured. The supplier must first be an approved supplier on the aerospace OEM's approved suppliers list. This involves the OEM performing an audit on the supplier to determine whether the correct certification, documentation, and processes are in place and are being applied. Once the supplier has been approved, the organisation can bid for OEM contracts. After receiving a contract, the supplier must perform a first article inspection (FAI) and submit it to the OEM in the form of a Production Part Approval Process (PPAP) file for their approval. The planning and risk management phase must be performed when performing the FAl. The manufacture of parts for the FAl must follow the full process shown in Figure 8 and the relevant procedures. Once the FAI has been approved by the OEM, the part realisation process is frozen, and the supplier can begin to manufacture the parts. For repeat orders, the full planning and risk management phase need not be performed. The design documentation can be pulled from the document store and production can be scheduled, although it is customary to perform an additional FAl at the beginning of each order. However, the lessons learnt from each production run must be fed back into the Advanced Product Quality Planning (APQP) process to update the failure modes and effects analyses, and a check must be performed to confirm that the design documentation is still in order. This is essential for continual improvement and to ensure that the PPAP is a 'living document'.

The part required by the OEM must be categorised, based on the manufacturing and failure risks, to determine the type of post-processing and stringency of testing and inspection needed. NASA MSFC-STD3716 can be used as a best practice for categorising parts, along with DIN 65124 and ISO 17296-3, based on their application and risk [22][23][24]. Ultimately the organisation must develop and test a part categorisation procedure to assign risk mitigation strategies effectively. This forms part of the APQP and risk management procedure.

\subsubsection{Powder management}

Powder management is an integral part of ensuring that conforming parts are manufactured. The organisation must develop a recycling strategy using SPC and qualification testing to determine the required blending ratios of virgin and used powder, and the allowable lifespan for the powder. These strategies must correlate with the part categories. For example, lower-risk parts may be manufactured from powder that has experienced more reuse and longer ageing. Each recycling strategy must be documented to form a separate SOP in the organisation's QMS. 


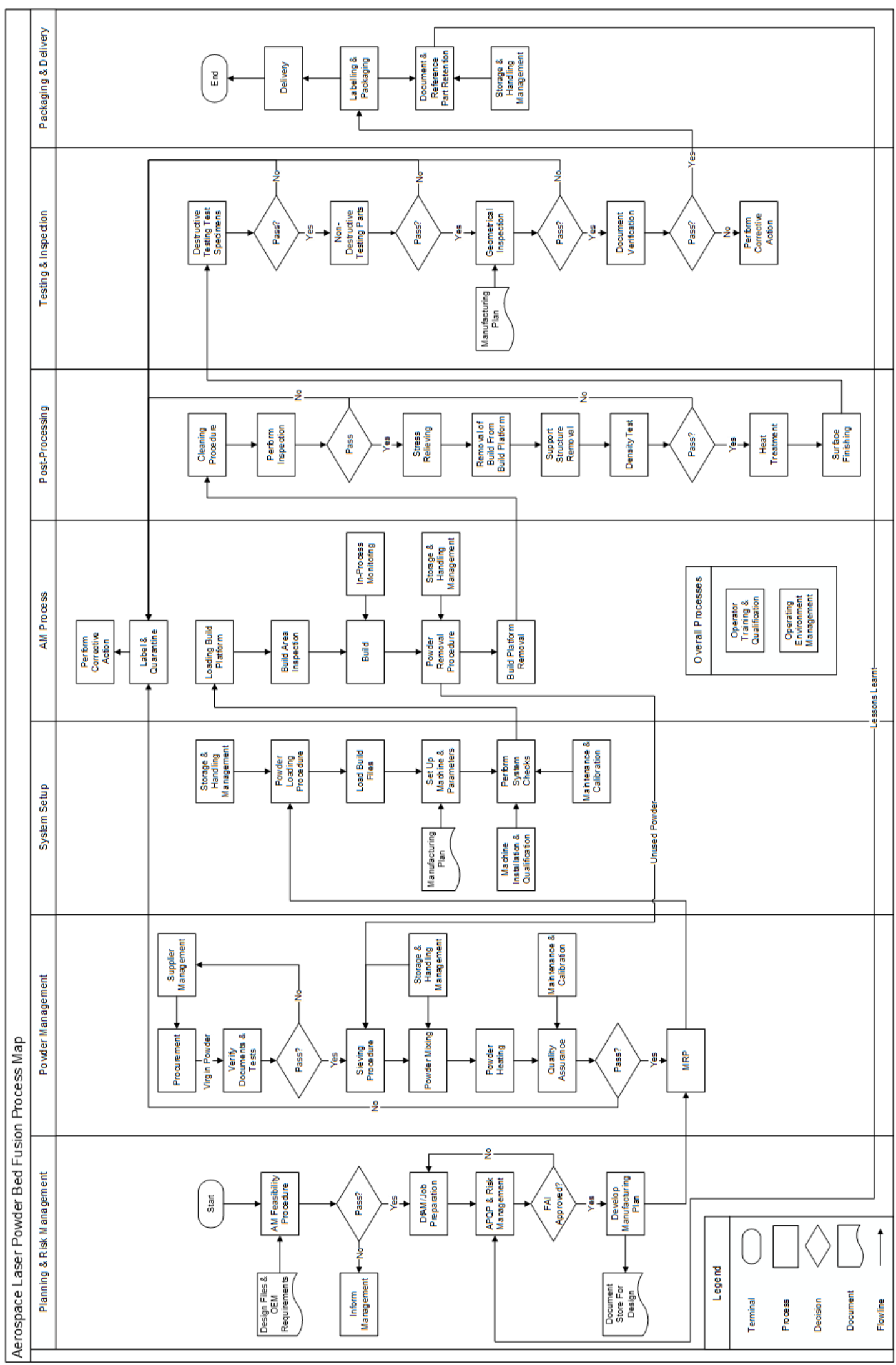

Figure 8: Aerospace LPBF process map 
The organisation must monitor the powder feedstock supplier. This supplier must be certified in accordance with AS 9100D, and the organisation must perform sample testing on deliveries to ensure that the CoC and the relevant quality assurance documentation are in order. With effective temperature and humidity controls and closed-loop powder management systems, the moisture content in the powder can be controlled to the extent that procedures such as powder drying are not needed; this is preferred in the industry. Table 4 presents an example of an SOP for powder quality assurance.

Table 4: Example of powder quality assurance SOP

\begin{tabular}{|c|c|}
\hline \multicolumn{2}{|l|}{ QMS-SOP-207 } \\
\hline $\begin{array}{l}\text { Applicable } \\
\text { standards }\end{array}$ & ASTM F3049, ASTM F3303, ASTM B215, DIN 65122, ASTM 2924, ISO 17296-3 \\
\hline Requirements & $\begin{array}{l}\text { The mixed powder must be tested to ensure that it meets the required specifications. ASTM B215 } \\
\text { must be followed for the sampling of metal powders and, at a minimum, the tests depicted in } \\
\text { ASTM F3049, DIN } 65122 \text {, and ISO } 17296-3 \text { must be followed in testing the powder feedstock. At a } \\
\text { minimum, the following tests must be performed: } \\
\text { - } \quad \text { Density (Apparent - ISO 3923, Tap - ASTM B527). } \\
\text { - PSD (ISO } 13320,13322,4497, \text { ASTM B822, B330). } \\
\text { - } \quad \text { Flow rate (ISO 4490, ASTM B213, B964). } \\
\text { - Compressibility (ASTM B331). } \\
\text { - Chemical composition (ISO 7625, ASTM E2371, 1409). } \\
\text { - Morphology (ISO 9276, DIN 65122). } \\
\text { - Surface (ISO } 9277) \text {. } \\
\text { Procedures must be developed for each of the tests required by this SOP. Any other tests required } \\
\text { by the OEM must also be performed. The QA procedure must clearly define what determines a } \\
\text { nonconformance. If the batch being tested passes all the required tests, it must be issued with a } \\
\text { CoC. The powder batch must be labelled with the recycling strategy used, the critical testing } \\
\text { values, the date recycled, and for which part category it may be used. }\end{array}$ \\
\hline
\end{tabular}

Supplier management is identified as a high-risk area when expanding the ISO 13485 QMS to include the AS $9100 \mathrm{D}$ requirements. Suppliers must be assessed and monitored to ensure that they meet the requirements of AS $9100 \mathrm{D}$ and of the OEM.

\subsubsection{System setup}

The setup of the LPBF system is performed by a qualified operator. The procedures stipulating how the system is to be set up must be developed by consulting the machine manufacturer, as machines from different manufacturers differ significantly in their design and capabilities. During the machine qualification process, machine parameters are tested to determine their values for each part category. When a part manufactured on a set process is approved, the machine parameters must be saved in a build file to ensure that these parameters remain constant throughout production.

\subsubsection{AM process}

The AM process is also dependent on the type of LPBF system installed. The machine manufacturer must therefore be consulted when developing the procedures for the AM process.

The inspection of the build area is the last preventative action before the build process begins. The operator must sign off that this inspection was performed, as from this stage onwards only corrective actions can be performed.

\subsubsection{Post-processing}

Operators performing post-processing operations must be qualified to do so for each specific item of equipment. If post-processing is to be performed by a third-party organisation, it must have the relevant accreditation (such as AS 9100D, Nadcap AC 7102) to do so, and it must be approved by the OEM. This organisation must also be periodically monitored, as per AS 9100D.

Stress relieving and HIP are typical aerospace heat treatments for Ti-6 Al-4 V parts manufactured via LPBF, and are special processes requiring Nadcap accreditation. The post-processing to be performed on the parts must be approved by the OEM for the specific part application. This is performed via the PPAP and FAI process. The type of heat treatment is dependent on the application of the part. A separate procedure must be developed for different heat treatments in case they are required by the OEM. 
Part density is tested before HIP and further post-processing to save post-processing costs if a nonconforming part is detected. Testing during qualification must be performed to determine what type of HIP process must be performed, depending on the density measured.

Surface finishing and machining has a significant effect on part quality and fatigue life, and the design team must consider it in the planning and risk management phase. Certain surface finishing methods are special processes, and require Nadcap accreditation.

\subsubsection{Testing and inspection}

There are both advantages and disadvantages to performing testing and inspection in-house; and these must be considered by management. An advantage is that the organisation can control and monitor the testing and inspection procedure better if performed in-house; the disadvantages are that it is expensive to install all the necessary equipment and to obtain the necessary certifications and operator qualifications. If the organisation is to perform testing and inspection procedures in-house, the equipment must be calibrated by an organisation that is accredited in accordance with ISO/IEC 17025. Personnel performing testing and inspection procedures need to be certified according to industry requirements such as ISO 9712 .

For general production, destructive testing (DT) procedures must be performed on witness specimens; whereas, for the FAI process, DT might be required by the OEM on the parts themselves. The product realisation process can only start non-destructive testing (NDT) once it has been determined, through DT, that the witness specimens are of the required quality. NDT is performed on all parts, both for general production and for FAI. Some OEMs will require that NDT be performed on witness specimens as well.

For the testing and inspection of aerospace LPBF parts, it is important to test for anisotropy (test specimen must encompass $\mathrm{X}, \mathrm{Y}$, and $\mathrm{Z}$ directional behaviour) and fatigue behaviours. These results must be assessed against the requirements of the intended use of the part. The testing and inspection methods are dependent on part geometry, material, features, surface condition, and application [23].

\subsubsection{Packaging and delivery}

The requirements for packaging and delivery are highly dependent on the OEM's requirements and preferences. The OEM must be consulted to determine these requirements for each part category. The labelling on each part must contain the required unique identifiers to trace all the procedures, equipment, materials, and personnel involved in the realisation of that part.

\subsubsection{Overall procedures}

Overall procedures are those that apply either to many sections of the aerospace LPBF value chain or to the value chain as a whole. These procedures must be developed and be adhered to before the first production run is performed. Key procedures include machine installation, machine qualification, maintenance and calibration, operating environment management, and operator training. Employees must be trained and made aware of the requirements of AS 9100D and how they can uphold the values of the standard. The procedure for machine qualification ensures that special processes can repeatedly produce parts of the required quality [25].

\subsubsection{Validation}

For validation by experts, an eight-question questionnaire was set up. A pilot interview was performed with an expert during which improvements were identified and the questionnaire was refined. This questionnaire was semi-structured to encourage the experts to suggest improvements if required. Experts were asked to provide input only on the areas of the framework in which they had expertise. A conformance rating of 1 to 5 was included in the questionnaire, and experts were asked to apply this rating system and to comment on their reasoning. Table 5 presents the responses received by the experts. A total of seven experts from academia and industry provided input.

A conference paper was published based on the findings of this objective, focusing on the qualification requirements for LPBF systems for aerospace applications. This paper was subject to a double bind peerreview process, and was presented at an international AM conference [25]. 


\begin{tabular}{|c|c|}
\hline Response & $\begin{array}{l}\text { The response was that there is a good to high inclusion of processes and activities. One expert } \\
\text { suggested including financial controls, and another suggested including a design simulation process. }\end{array}$ \\
\hline \multicolumn{2}{|r|}{ 2. Are these processes and activities in the correct order, and are the connections between them correct? } \\
\hline Response & $\begin{array}{l}\text { The feedback from the experts was good to high. One expert suggested ensuring that organisational } \\
\text { processes are incorporated in accordance with ISO 9001; this was addressed in accordance with AS } \\
9100 \mathrm{D} \text { for aerospace. }\end{array}$ \\
\hline \multicolumn{2}{|c|}{ 3. How relevant are the identified standards for the procedures? } \\
\hline Response & $\begin{array}{l}\text { Of the experts who were qualified to respond to this question, a good to high response was received. } \\
\text { One expert stated that all relevant standards had been identified and covered, and another suggested } \\
\text { determining the adequate number of tests to be performed through implementation testing for specific } \\
\text { design categories. }\end{array}$ \\
\hline \multicolumn{2}{|r|}{$\begin{array}{l}\text { 4. How well do the descriptions of the procedures cover the needed aspects for the certification of LPBF } \\
\text { aerospace parts? }\end{array}$} \\
\hline Response & $\begin{array}{l}\text { The response was good. Of the experts who responded, all agreed that the descriptions that were } \\
\text { provided accurately described the required actions and provided a clear view of what was required for } \\
\text { qualification and certification. }\end{array}$ \\
\hline \multicolumn{2}{|c|}{ 5. Is this framework representative of how parts are certified in the aerospace industry? } \\
\hline Response & $\begin{array}{l}\text { Of the experts who were qualified to respond, all agreed that this framework was rep } \\
\text { how parts are certified in the aerospace industry, with one expert highlighting that ac } \\
\text { implementation testing would be needed. }\end{array}$ \\
\hline \multicolumn{2}{|c|}{ 6. Is the framework easy to understand and apply? } \\
\hline Response & $\begin{array}{l}\text { According to the responses from the experts, the framework was easy to understand and apply, } \\
\text { one expert disagreeing about new users, as he felt that new users would need background LPBF } \\
\text { knowledge and training on the applicable standards. }\end{array}$ \\
\hline \multicolumn{2}{|c|}{ 7. Is there a need for this framework in the industry, and which gaps will it help to solve? } \\
\hline Response & $\begin{array}{l}\text { The experts agreed that this framework was needed. Two experts saw the benefit of this framework as } \\
\text { an in-house process for emerging companies. Another two noted that established companies in the } \\
\text { industry have equivalent frameworks, but that it would be beneficial to have a standardised } \\
\text { framework. }\end{array}$ \\
\hline \multicolumn{2}{|c|}{ 8. Do you have additional comments or recommendations? } \\
\hline Response & $\begin{array}{l}\text { In the additional comments and recommendations, one expert suggested expanding the framework to } \\
\text { include all AM technologies. Another suggested defining thresholds, including mechanical properties, } \\
\text { monitoring aspects, and microstructure. Additional suggestions were made to assess the cost of } \\
\text { performing such procedures. }\end{array}$ \\
\hline
\end{tabular}

\section{$5 \quad$ DISCUSSION AND CONTRIBUTION}

As the framework presented in this study is conceptual, implementation testing through a case study is needed to quantify the effectiveness that this framework provides to the industry, and to define and qualify procedures such as part categorisation. Consulting experts to validate the proposed framework provided promising results, and suggested that, as a concept, the framework does provide value to the industry. As suggested by the experts, refining certain areas, such as determining an adequate number of quality assurance tests, would be required. These details should be determined through the implementation of the framework. The economic implications of the framework were highlighted by the experts. This was excluded from the scope of this study, but should be addressed in future studies. This research provides industry with QMS requirements that are important to the aerospace industry, as well as a framework for developing procedures that meet industry and customer requirements for parts manufactured by the LPBF process.

\section{CONCLUSION}

The development of the framework presented in this study followed systems engineering principles and a top-down approach. A gap analysis comparing ISO 13485 and AS 9100D was performed to identify high-risk requirements that should be focused on when expanding an organisation's medical device QMS to include aerospace requirements. The benchmarking technique was then applied to identify and analyse the 'best in class' processes of both the aerospace and the AM industries in South Africa. The key characteristics of these processes were used to synthesise the aerospace LPBF value chain and to represent the high-level processes required for the realisation of aerospace parts. The process standardisation technique was then applied to modularise the value chain into sub-processes and activities, and industry standards and best 
practices were identified for each sub-process and activity, and used to determine the requirements for SOPs.

The certification of aerospace parts is a complex function with many aspects. This research identified these aspects for AM production and, through process standardisation and mapping, provided a systematic method for achieving QMS certification in the form of a framework. The framework was developed in such a way as to aid companies in attaining AS 9100D certification. Through the application of this framework, AM companies can plan for certification from the beginning, and reduce the costs and complexities involved in becoming AS 9100D-certified.

\section{REFERENCES}

[1] Wohlers Associates. 2019. Wohlers report 2019: 3D printing and additive manufacturing: State of the industry.

[2] Defence IQ. 2016. Additive manufacturing in aerospace, defence \& space: Trends and analysis 2016.

[3] AMSC. 2018. Standardization roadmap for additive manufacturing (version 2).

[4] ISO. 2016. Medical devices - Quality management systems - Requirements for regulatory purposes (ISO 13485:2016). BSI.

[5] SAE International. 2016. Quality management systems: Requirements for aviation, space, and defense organizations (AS 9100D:2016).

[6] DNV GL. 2017. Additive manufacturing: Qualification and certification process for materials and components (DNVGL-CG-0197).

[7] Monzón, M.D., Ortega, Z., Martínez, A. \& Ortega, F. 2015. Standardization in additive manufacturing: Activities carried out by international organizations and projects. International Journal of Advanced Manufacturing Technology, 76, (5-8), pp. 1111-1121.

[8] Krueger, H. 2017. Standardization for additive manufacturing in aerospace. Engineering, 3(5). pp. 585

[9] Taylor, R.M., Manzo, J. \& Flansburg, L. 2016. Certification strategy for additively manufactured structural fittings. In Proceedings of the 27th Annual International Solid Freeform Fabrication Symposium. Austin, Texas, USA. Bourell, D.L., Crawford, R.H., Seepersad, C.C., Beaman, J.J., Fish, S., Marcus, H. pp. 1985-2000.

[10] Portolés, L., Jordá, O., Jordá, L., Uriondo, A., Esperon-Miguez, M. \& Perinpanayagam, S. 2016. A qualification procedure to manufacture and repair aerospace parts with electron beam melting. Journal of Manufacturing Systems, 41, pp. 65-75.

[11] O'Brien, M.J. 2019. Development and qualification of additively manufactured parts for space. Optical Engineering, 58(1), pp. 1-10.

[12] Meneghin, I, Ivetic, G, Stiller, M, Molinari, G, Ristori, V, Della Ratta, S, Dumont, F. \& 2019. Fatigue in additive manufactured aircraft: The long way to make it fly. In Proceedings of the 30th Symposium of the International Committee on Aeronautical Fatigue. Krakow, Poland. Niepokólczycki, A., Komorowski, J. pp. 16-30.

[13] Rummler, G.A. \& Brache, A.P. 2013. Improving performance: How to manage the white space on the organizational chart. Third ed. San Francisco, USA. Jossey-Bass,

[14] Greyling, H., Du Preez, W.B., De Beer, D. \& Uys, A. 2017. Collaborative program in additive manufacturing.

[15] ISO. 2018. Risk management: Guidelines (ISO 31000:2018). BSI.

[16] The Open Group. 2018. The TOGAF® Standard, Version 9.2.

[17] ISO. 2019. Information processing: Documentation symbols and conventions for data, program and system flowcharts, program network charts and system resources charts (ISO 5807:1985).

[18] de Vries, H.J. 1999. Standardization: A business approach to the role of national standardization organizations. First ed. New York, USA. Springer.

[19] Münstermann, B. \& Weitzel, T. 2008. What Is process standardization?. In International Conference on Information Resources Management (CONF-IRM).

[20] Graziano, A.M. \& Raulin, M.L. 2014. Research methods: A process of inquiry. Eighth ed. London, UK. Pearson.

[21] Gibbons, D.W. \& van der Merwe, A.F. 2019. "Transitioning from ISO 13485 to AS 9100D for an additive manufacturing company," in 20th Annual RAPDASA Conference: The Future of Manufacturing Layer by Layer. Bloemfontein, South Africa. van der Walt, K. pp. 121-128.

[22] NASA. 2017. Standard for additively manufactured spaceflight hardware by laser powder bed fusion in metals (MSFC-STD-3716).

[23] DIN. 2018. Aerospace series: Technical specifications for additive manufacturing of metallic materials with the powder bed process (DIN 65124).

[24] ISO. 2016. Additive manufacturing: General principles Part 3: Main characteristics and corresponding test methods (ISO 17296-3:2016). BSI.

[25] Gibbons, D.W. \& van der Merwe, A.F. 2019. "Qualification and control of metal laser powder bed fusion systems for aerospace applications," in 20th Annual RAPDASA Conference: The Future of Manufacturing Layer by Layer. Bloemfontein, South Africa. van der Walt, K. pp. 171-179. 